\section{A comparison between two indirect potentiometric procedure for determination of sodium and potasium concentrations in serum - FLEXOR EL 200 ELITech vs Rapidlab 348 - Bayer}

\section{DOI: $10.1515 / \mathrm{rrlm}-2016-0040$}

The constancy of the concentration of electrolyte elements in plasma, such as sodium and potassium, are of paramount importance for the functioning of metabolism (1). The occurrence of plasma changes of these electrolytes causes systemic damage to the body. Disorders such as changes in osmolarity and blood volume influence the patient's clinical and therapeutic course of choice, especially in hospital emergencies (2).

Regarding laboratory tests for measuring electrolyte concentrations, criterion and effectiveness during its analysis and speed of the diagnostic reports' delivery assist the clinician in the action to be taken (3).

Among the methods for laboratory analysis, potentiometric performed by means of ion - selective electrodes is a well-known technique for chemists and represents a small portion of of electroanalytical field (4).

In 1897, Nernst developed the first hydrogen electrode capable of measuring the acidity of an aqueous solution, this discovery took place a decade after he described the equation potential between a metal and a solution, initiating the study of potentiometry (5). Haber and Klemensiewiez first mentioned the glass electrode in 1909 in an article the glass electrode and its clinical use (6). In the same year, biochem- ist Soren Sorensen proposed the $\mathrm{pH}$ scale while working for the brewing industry for the purpose of facilitating measures for the quality control of the product. After these discoveries the studies and improvements on the electroanalytical field made significant progress.

The ion - selective electrodes (ISEs) are electrochemical sensors that allow the potentiometric determination of the activity of an ionic species in the presence of other ions (7). The use of ISEs permits the analysis of several analytes with limits detection at levels from parts per trillion (10$10 \mathrm{~mol} \mathrm{~L}-1)$, thus affording further studies by reading minimum particle concentrations (8).

According to ISO 15189 , it is greatly important in a clinical laboratory to review and periodically update the values of laboratory tests of references according to the population studied, as well as when there is a change of analytical procedures, or even the introduction of new technologies (9).

In the Clinical Laboratory of the Faculty of Medicine of $\mathrm{ABC}$, a prior comparative study of specific quantification of sodium and potassium electrolytes through indirect potentiometric dosage by ion - selective electrodes used two different devices, an automated one (Flexor el 200 - ELITech) and a semi-automated (Rapidlab 348 - Bayer), both commercially available.

In this study, 204 blood samples were used of patients seen and accompanied by the service Clinic of the Faculty of Medicine of ABC.

The concentrations of electrolytes sodium and potassium were measured in serum obtained by venipuncture collection, respecting the sequential order of blood tubes indicated by the Brazilian Society of Clinical Pathology (10) when using the closed collection system. 
After collecting blood, the serum was briefly separated from the blood cells to avoid an ionic imbalance resulting from cellular metabolism and the change in $\mathrm{pH}$. Samples were centrifuged in less than 01 hour after blood sampling, at 2,500 RPM for ten minutes, in sequence the analysis of sodium and potassium concentrations were performed. The concentration ranges of the two measured analytes were: sodium 5 to $250 \mathrm{mEq} / 1$ and potassium 0.5 to $20.0 \mathrm{mEq} / \mathrm{L}$.

Patients were requested to have fasted for at least eight hours prior to the time of blood collection to prevent preanalytical errors on interference of the analytes measure. We excluded Lipemic, hiperproteinimic, and hemolyzed samples.

To analyze concordance the following methods were used: Lin's concordance, Pearson correlation and Bland \& Altman analyses. For all analyses, we used a confidence level of $95 \%$. The Stata version 11.0 was used for data analysis.

We tested two different devices using the same method for quantification of electrolytes sodium and potassium in the blood plasma. The results of the analytes of potassium electrolytes

A)

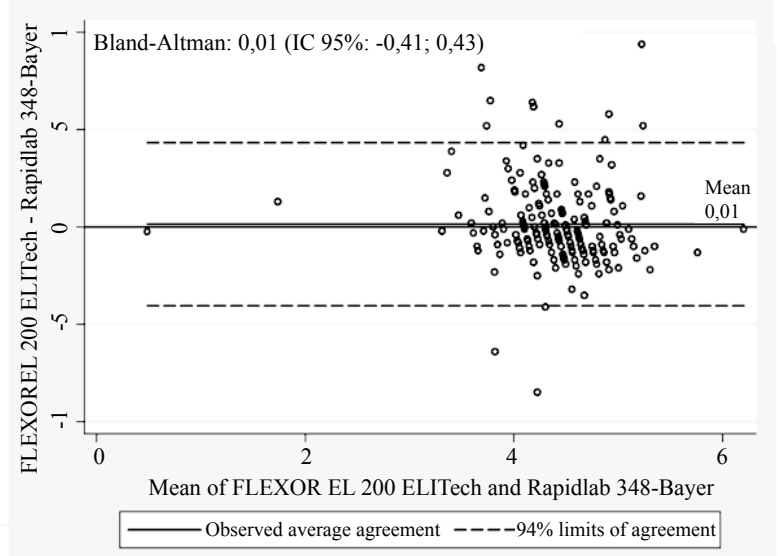

showed a $95 \%$ confidence interval, with significance 0.01 . The relation showed between the variables in the sample is a highly reliable indicator, and similar results showed correspondence between devices when tested.

In the analysis of sodium electrolytes, confidence interval was -3.17 , without significant values. The lack of comparability for sodium was the same without taking into its consideration concentration in the blood. The results showed no equivalence, which means no reproducibility of the results analyzed in the two devices, even with the same principle (i.e. ion selective electrode).

Frequent evaluation of the results of laboratory tests has great value in clinical research, diagnosis, and prognosis of patients. Thus, the results of laboratory tests show good characteristics such as reproducibility, precision and accuracy values with high sensitivity and efficiency.

In clinical laboratories, it is currently common to use two equipments or more for each sector (called "back up" machine). These devic-

B)

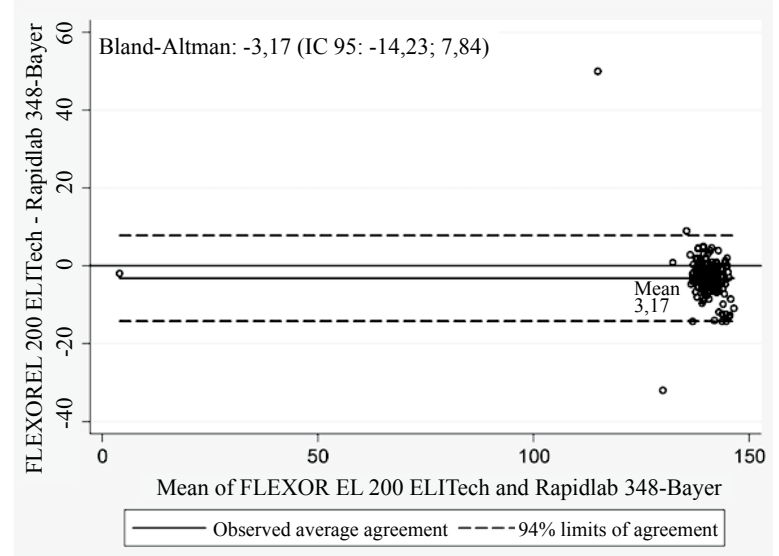

Figure 1. Plot of differences between FLEXOR EL 200-ELITech and Rapidlab 348-Bayer vs. the means of the two measurements. In figure $A$ bias of 0.01 units of potassium is represented by the gap between the $X$ axis, corresponding to a zero difference, and the parallel line to the $X$ axis at 0.01 units. Bias of -3.17 units of Sodium is represented by the gap between the $X$ axis, corresponding to a zero differences, and the parallel line to the $X$ axis at $\mathbf{- 3 . 1 7}$ units (Figure B). 
es do not necessarily have the same brand, but mostly have the same principle of analysis.

The results of samples should hold the same principle even on different technologies showing corresponding results. In case of sodium and potassium, electrolyte results are expressed in milliequivalents and discrete changes in the values of these concentrations suggest the correspondence of the sample to confirm the result. In our study, the results of sodium analytes showed no correspondence in the values of the two different equipment. Serum analysis performed on distinct analyzers could suggest a consistency of results, as showed in potassium analyses.

This research did not receive any specific grant from funding agencies in the public, commercial, or not-for-profit sectors. No potential conflict of interest relevant to this article.

\section{Fernando Fonseca ${ }^{1}$, Thais Belardo ${ }^{1}$, Renata Salatini2,*, Joice Anaize Amaral ${ }^{2}$, Edimar Pereira ${ }^{3}$, Rodrigo Raimundo ${ }^{4}$}

1. Faculdade de Medicina do ABC, São Paulo, Brazil;

2. Faculdade de Medicina da Universidade de São Paulo, Brazil;

3. Universidade Federal de São Paulo, Brazil;

4. Faculdade de Saúde Pública da Universidade de São Paulo, Brazil.

* Corresponding author: Renata Salatini, Faculdade de Medicina da Universidade de São Paulo, Brazil, e-mail: resalatini@yahoo.com

Received: $22^{\text {th }}$ July 2016; Accepted: $22^{\text {th }}$ October 2016; Published: $28^{\text {th }}$ October 2016.

\section{References}

1. Louden JD. Regulation of fluid and electrolyte balance. Anaesth Intensive Care Med. 2012 Jul;13(7):302-8. DOI: 10.1016/j.mpaic.2012.04.009.

2. Vaughan-jones RD, Boron WF, Gennari FJ. Integration of Acid-Base and Electrolyte Disorders. N Engl J Med. 2015;372(4):389-92. DOI: 10.1056/NEJMc1414731.

3. Lan WJ, Zou XU, Hamedi MM, Hu J, Parolo C, Maxwell EJ, et al. Paper-based potentiometric ion sensing. Anal Chem. 2014;86(19):9548-53. DOI: 10.1021/ ac5018088.

4. Albert V, Subramanian A, Rangarajan K, Pandey RM. Agreement of two different laboratory methods used to measure electrolytes. J Lab Physicians. 2011;3(2):1049. DOI: $10.4103 / 0974-2727.86843$.

5. Fernandes JCB, Kubota LT, de Oliveira Neto G. Eletrodos íon-seletivos: histórico, mecanismo de resposta, seletividade e revisão dos conceitos. Quim Nova. SBQ; 2001 Feb;24(1):120-30. DOI: 10.1590/s010040422001000100020 .

6. Marczewska B, Marczewski K. First Glass Electrode and its Creators F. Haber and Z. Klemensiewicz - On 100th Anniversary. Zeitschrift für Phys Chemie. 2010 May;224(5):795-9. DOI: 10.1524/zpch.2010.5505.

7. Ruzicka J. The Seventies - Golden Age for Ion Selective Electrodes. J Chem Educ. 1997;74(2):16770. DOI: $10.1021 /$ ed074p167.

8. Ardeshiri M, Jalali F. Highly selective electrode for potentiometric analysis of methadone in biological fluids and pharmaceutical formulations. Mater Sci Eng C Mater Biol Appl. 2016 Jun 1;63:30-6. DOI: 10.1016/j. msec.2016.02.050.

9. ABNT NBR. ABNT NBR ISO 15189 - Laboratórios Clínicos - Requisitos de Qualidade e Competência. 1. ed. Rio de Janeiro: Associação Brasileira de Normas Técnicas; 2015. 60 p.

10. Sociedade Brasileira, Laboratorial Patologia Clínica/ Medicina. Recomendação da Sociedade Brasileira de Patologia Clínica/Medicina Laboratorial para Coleta de Sangue Venoso. 2. ed. Tamboré: Editora Manole Ltda.; 2010. 130 p. 